\title{
A FRAMEWORK OF KEY ENABLING DRIVERS FOR INNOVATION: PERCEPTIONS OF COMMUNITY ENGAGEMENT SCHOLARSHIP OF SCIENCE FAIRS
}

\section{D. Gibbs*}

Faculty of Business Economic Sciences

e-mail: marilyn.d.g28@gmail.com

\section{P. Poisat*}

Faculty of Business Economic Sciences

e-mail: paul.poisat@mandela.ac.za

*Nelson Mandela University

Port Elizabeth

\section{ABSTRACT}

The focus of the article is to identify the main drivers for creating an innovative thinking environment, within the context of a community engagement project. Utilising reflexive practice with an analytical auto-ethnography approach, drivers of innovative thinking were identified from the field and experiences utilising existing theory in an educator, learner and community framework for driving innovation. The theoretical underpinnings of the three pillars used as the foundations for this framework were selected from literature in the people, place and process/purpose domains. Specifically, these were: Community Engagement Scholarship (people); creative Transdisciplinary Spaces (place) and Enabling Knowledge with common team vision (process/purpose). Certain pedagogical pathways were identified as critical enablers for driving innovation in this context: pedagogy, teaching strategies, mentoring, application-inquirybased, safe spaces, critical thinking across disciplines, common vision, communication and collaboration. A framework of critical pedagogical pathways was proposed to drive creativity and innovation.

Keywords: innovation, Community Engagement Scholarship, science fairs, auto-ethnographic, Transdisciplinary Spaces, inquiry-problem-based, critical thinking.

\section{INTRODUCTION}

Creative and innovative thinking skills are essential for twenty first century innovators and researchers. Since thinking skills are often grounded so solidly in the curriculum at secondary schools, the mind-set change to think differently becomes a quantum leap. Educators need to be able to create a unique pedagogical pathway that can unlock the key enabling drivers or factors that increase innovation and higher order critical thinking skills in the minds of 
educators and learners.

It is important to identify what these key enabling factors are. The primary research question can thus be formulated as: "What enabling factors and overall framework can be identified as being the main drivers for creating an innovative thinking environment, within the context of a community engagement project (i.e. science fair participation)?" The study aligns with the viewpoint of De Beer $(2013,2)$, who argues that knowledge is generated "not in insulated spaces but in real life contexts of local urban communities". It is in this applicationbased, enquiry driven thinking, that discovery learning takes place, which in turn catalyses a higher engagement of both teaching and learning, as well as creative, critical and innovative thinking (RSA DHET 2013, 10).

Very few holistic research frameworks on driving innovation have been published within the community engagement space, especially in the South African context of science fairs. As stated by Erasmus and Albertyn $(2014,30)$, this common focus of community engagement projects in higher education on "creative problem-solving for change through research processes" could act as the platform for survival and sustainability. The justification of this study is to fill that gap and propose an integrated, uniquely designed framework that can act as a map for designing the landscape for increasing future innovative thinking in this domain. This article is positioned within this community engagement space and landscape, in the intersection of academia and community, where Enabling Knowledge is created by this overlap.

This article explores a devised framework, drawn from the experiences of a researcher leading a community project of co-ordinating and mentoring both educators and learners, in designing science expo projects beyond the curriculum, which are exhibited at science fairs. For this article, science fairs can be defined as exhibitions of science projects completed by learners from junior to senior level at a school, district, regional or international level. The collected findings of the identified key enablers for innovation were extracted from the perceptions and feedback of educators and learners involved in the teaching and learning experience and the participants of science fairs, both regionally and internationally. This participation in science fairs involve the educator, learner and the community in an experience that embraces an inquiry-based, discovery teaching strategy, with a project-based learning method. The research study of reflexive practice, with an analytical auto-ethnography approach was used. The researcher and the team were involved in co-ordinating all of the aspects around operationalising science fairs as a regional project of a stakeholder. By being directly involved in this community engagement interface and working directly with community educators, learners, stakeholders, industry, academia and government, several observations of outcomes and experiences were recorded and reflected upon. 
It must be noted that the researcher's findings and observations were infused into the theoretical underpinnings from literature. The selected theoretical framework underpinning pillars were sourced from literature, after the science fair observations and data collection. The data was collected from journals, evidence, project programs, data bases, event reports, interviews and reflective practice from the researcher's experience of being part of the organising committee. Based on the praxis from reflexivity in this specific learning space of science fair participation, the key enabling drivers were outlined. Observations and feedback of the key enabling drivers of educator, learner and community in these scenarios were collected and coded, with key selected enablers outlined in this article. These led to an elucidated framework for driving innovation through community engagement, as it was then integrated with the theoretical literature. This integrated devised framework was constructed on the foundation blocks of the three broad focus areas of educator, learner and community.

This proposed and designed, unique strategic framework contributes to the knowledge in this domain and could act as a guide for NPOs (Non-profit Organisations) to drive higher innovative thinking and the level of inquiry, critical and higher order thinking skills.

Creativity and critical higher order thinking, can be defined as the development of novel and useful ideas, utilising higher order thinking skills (Anderson et al. 2001; Liu, Liao and Loi 2012). The concept of innovation can be characterised by knowledge interactions that contribute to unique and novel solutions to complex problems (James, Guile and Unwin 2013, 249). Both innovation and critical thinking skills need to be improved in both educators and learners and thus aligned with this thinking, James, Guile and Unwin (2013) recognise the importance of innovation, creativity and knowledge for survival.

In the community, new spaces are required to enable this type of thinking and facilitate this drive for innovation and unique skill sets that may be required in the future. Therefore, the aim of this article is to report on a framework of these enabling factors that drive innovative thinking in the participation within Transdisciplinary Learning Spaces, which in this case is the participation in science fairs and the preparation workshops prior to the event. These experiences are for the educator, learner and community. The purpose of this devised framework is to assist educators, learners and the community in elucidating the enabling factors that drive this innovative thinking in an observed, real application of science fair participation.

\section{LITERATURE REVIEW: DRIVING INNOVATIVE THINKING}

In the review of the relevant literature, various concepts of selected enabling factors that drive innovative thinking levels in the broad context of community engagement are discussed. 


\section{Macro-context of the study and policies of South Africa}

It is important to contextualise the study so that the community engagement landscape and historical background of this research can be positioned correctly. It is known that community engagement contributes to "social justice, equity and transformation in the historical context of South African higher education and society" (Albertyn and Daniels 2009, 413). It is a challenge for knowledge partnerships between universities and third sector organisations such as Nonprofit Organisations (NPOs) to operate sustainably, due to financial constraints in the higher education sector. Working within the interface between higher education spaces and third sector organisations allows some interesting dynamics, and is a dialogic space that has not yet been rigorously explored and researched in South Africa (Erasmus and Albertyn 2014).

To popularise science among the public by promoting science and communication, requires Community Engagement Scholarship and a form of mutual learning for effective outcomes (RSA, DST 2017). In the South African context, the Bio-Economy Strategy (RSA, DST 2013) outlines some key mechanisms that are needed to coordinate innovation efforts. Role players should contribute rather than compete for opportunities, resources and outcomes. In South Africa, the Department of Science and Technology Report (RSA, DST 2013) outlines the development of the underpinning strategic competencies that are required to drive innovation. These include the development of the full value chain, incubation facilities, human capital development, knowledge management, intellectual property management as well as the development of strategic innovation programs. Effective coordination and communication across the many disciplines will guide science capabilities and identify gaps. A devised innovation framework at the operating level will be of value for implementation in the education space, especially at the teaching and learning level.

\section{Creative and innovative thinking and high cognitive thinking levels}

Creative thinking as a higher level of cognitive thinking can be framed within Bloom's Taxonomy which describes educational cognitive theories. A theoretical framework for cognitive thinking levels is based on Bloom's Taxonomy of educational objectives (Krathwohl, Bloom and Masai 1964). The key levels in Bloom's are knowledge (retrieving information, remembering sequences, facts); comprehension; application; analysis, synthesis and evaluation. In the revised taxonomy of Anderson et al. (2001), the synthesis and evaluation levels change places and the last level is named creativity. To achieve these higher order thinking levels, teaching strategies need to be aligned and well-crafted to drive the creative higher order skills to create innovation.

If an innovation strategy is to be implemented in any organisation, a framework with 
relevant key enabling drivers that are critical in that context is required to be used for diagnosis and elucidation. In examining the observed data, three broad groups were identified as the foundation: educator, learner and community.

\section{ENABLERS FOR COMMUNITY ENGAGEMENT}

Previous literature indicates research undertaken by UNESCO in the knowledge for change (K4C) consortium (K4C, UNESCO 2017), as seeking new ways of learning and creating conditions needed for innovative models of research and research training. It is based on five pedagogical principles grounded in theories of knowledge that recognise the importance of linking academic and community knowledge. In their studies these are: orientation towards ethics and values; deep understanding of power and partnerships; multiple modes of enquiry; balance between classroom and field and developing critical and reflexive researchers. It was seen in this research study that the science fairs offered this space for the linking of academe and community knowledge.

In this article, the researcher examined the theory around community engagement as the context of the study. The Community Engagement Scholarship of a project (i.e. co-ordination of a science fair for school learners from grades 4-12) was in a space that intersected academe and the community, so the literature reviewed included the Community Engagement Scholarship, the Transdisciplinary Spaces and the Enabling Knowledge that were the main, broad principles contributing to community engagement.

Underpinning the key findings from this study, the main enabling pillars sourced from literature were outlined as: Community Engagement Scholarship (CES); Transdisciplinary Learning Spaces (TDL) and Enabled Knowledge (EK) (Erasmus and Albertyn 2014). These enabling literature pillar concepts are defined and briefly unpacked below.

\section{Community Engagement Scholarship (CES)}

Enabling factors that drive innovative thinking are examined in the context of Community Engagement Scholarship (CES). In this article, the following interpretation of Community Engagement Scholarship (CES) is used. CES can be referred to as collaborative research activities, service and teaching undertaken by university staff and community, that encompass both the "facets of community engagement (reciprocal knowledge sharing, partnerships, public purpose) intersected with scholarship (current discipline knowledge, peer review, inquiry based, constructivist approach and open to critique)" (Magaiza 2014, 63). 


\section{Transdisciplinary Learning Spaces (TDL)}

Transdisciplinary Learning Spaces can be described as local neighbourhoods or transdisciplinary engagement sites. These spaces are where different academic disciplines work together with practitioners to solve a real-world problem (De Beer 2013).

\section{Enabled Knowledge (EK)}

Enabled Knowledge, closely embedded in community contexts, needs to be crafted and expanded to create sustainable solutions relevant to the society in which the university is embedded (Van Rooyen and Ellis 2014). It can be defined as practise-based, reciprocal knowledge that develops in context and is "developed for the sake of social change, not for the knowledge itself" (Preece 2012, 224).

These three constructs were selected, from the reviewed literature, as the main areas of theoretical underpinnings in a community engagement framework: Community Engagement Scholarship, Transdisciplinary Spaces and Enabling Knowledge (Figure 1).

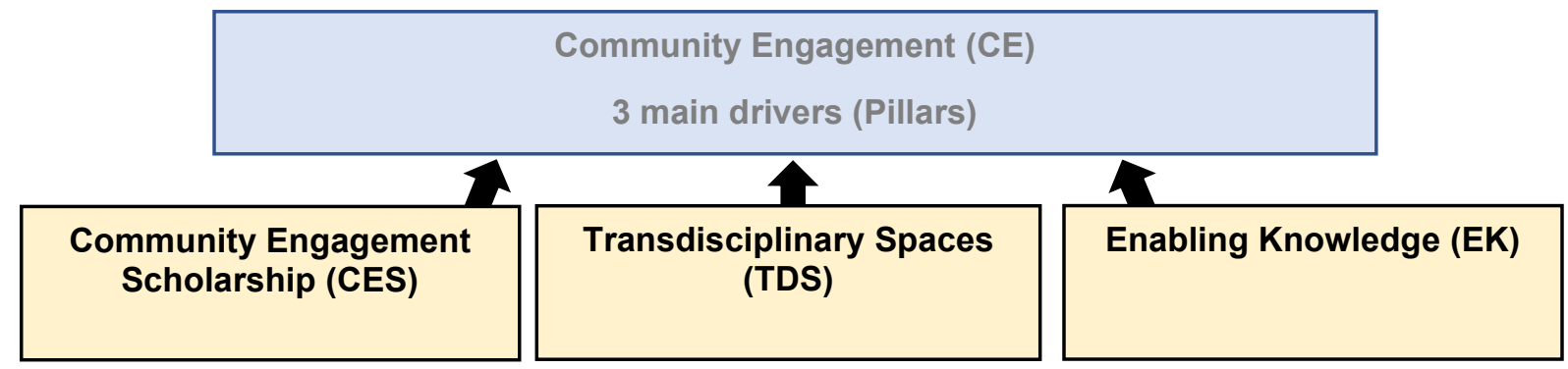

Figure 1: Outline of the selected theoretical framework pillars (Source: Various authors: Erasmus and Albertyn 2014).

In this research, using an analytical auto-ethnographic approach, the science fair experience was selected as the space in which the enabling drivers for innovation were observed. Data was collected from personal reflections of the researcher, the researcher's own experiences as well as reports, journals, projects and observations by the researcher.

\section{KEY FINDINGS OF ENABLERS OF INNOVATION: AUTO-ETHNOGRAPHIC APPROACH}

Auto-ethnography can be described as a research approach that seeks to describe and analyse (graphy) personal experiences (auto) to understand cultural and social experiences (ethno) (Manning and Adams 2015). It treats research as a political, socially-just and social-conscious act (Adams, Holman Jones and Ellis 2015). It is seen as both a process and a product. The 
researcher examined perceptions and feedback from participants in the science fairs from an analytical, auto-ethnographic approach. The author drew on their own experiences and journal notes, minutes and event reports to extend knowledge and understanding about the societal phenomenon, enabling drivers for innovation in science fairs.

The main, sub-constructs analysed from the narratives were found to fall into the three main domains of: People [Educator, Learner, Community: Engaged Scholarship]; Place [Creative spaces: Science Fairs/ Transdisciplinary Spaces] and Process/Purpose [Practice/Collaboration]. The researcher used the framework of Donaldson (2006) of people, place and purpose/process to filter the collected data into focused domains.

\section{People domain: Educator, learner and community: Engaged scholarship}

Many benefits may transpire in Community Engaged Scholarship (CES) (Magaiza 2014), as it provides the opportunity for participation in these spaces (such as science fairs), which can be at a school, district, regional or national level.

From both the learner and the educator viewpoints, a community engagement and shared excellence mentality is fostered in these "out of the curriculum" experiences. It was gathered from the participants, both educators and learners that they had "thoroughly enjoyed the research learning experience and discovered new pathways of thinking”. It was observed that many learners were starting out their investigations with a societal problem and then devising unique solutions that they could test. Examples include: designing a flame-retardant paint from household reagents for protecting shacks; salt water lamps from recycled materials and unique water saving devices.

As stated by De Beer $(2013,2)$, reimagining the Community Engagement (CE) of the higher education institutions with local communities would result in more sustainable transformations. Franklin, Sandman, Franklin and Settle (2008) allude to the fact that when universities engage with community, complex problems and real social needs of the country can be addressed. In this context, interdisciplinary engagement overlapping with indigenous knowledge can work in synergy. Science expos and fairs in South Africa are a national community engagement project and are aligned with the Department of Education curriculum outcomes.

In the analysis of the outcomes, it was noted that the learners and educators often undertook innovative and problem-solving science projects that addressed real life application of science in an inquiry-based method. These projects often crossed disciplines in the school subjects and the learner gained valuable skills in integrating and working across the silo subject spaces. Often complex problems were examined and projects that answer a societal need were 
tackled. High levels of critical thinking and innovative ideas were prevalent in the teams. Often the solving of real-life problems formed the basis of the aim of their science project and reallife applications and indigenous knowledge were prevalent. Examples of these types of projects included new wind turbine designs, water saving designs, spekboom usages and other indigenous plant materials with unique properties for societal applications.

In the narrative analysis, it was seen that the teacher's philosophy and pedagogy was an important driver of innovative thinking. In applying learning cycles, one can explore concepts, introduce concepts and then enter the application of the concept in a learner-centred activity.

Educators' knowledge of various teaching strategies are important as enablers. Innovative new teaching strategies that involve technology integrated teaching and learning, and inquiry and problem-based teaching strategies are all enabling modes of driving a culture of innovative thinking. This was noticeable in the level of innovation of the projects that were presented at science fairs where the educators encouraged a level of thinking outside of the curriculum and an application of higher critical thinking. Some teachers who did not want to tackle science projects, had little knowledge of the inquiry and problem-based teaching strategies.

A sound teaching philosophy that is holistic and inspires is imperative. Teaching a lesson that unpacks a concept holistically in a minds-on (knowledge or cognitive domain), hearts-on (attitudes and feelings, values, active responses or affective domain) and hands-on (application and psychomotor domain), can stimulate an effective and higher level of thinking (Van Rooyen and De Beer 2010). This is noted to occur in science project construction. Support may be given by parents and teachers, but ultimately if the learner has completed the project by themselves their communication of it will reflect in their passion and alignment. Cognitive outcomes relate to the mental processing of information by the learner and specify the action that they will be able to do because of the instructions. Cognitive outcomes are regarded as only minds-on outcomes. Teaching and learning only, at this level leads to the development of only the lowlevel thinking skills. The psychomotor domain involves utilising physical skills and equipment and is referred to as hands-on outcomes. The affective domain is described as the feelings, values and attitudes and is the hearts-outcome. By teaching to all of these outcomes, higher levels of thinking can be achieved. Embracing a holistic teaching philosophy includes a "making a difference in my community" aspect and it is this intrinsic motivation that drives one to be part of a team and enable collaborative partnership within the community (Van Rooyen and De Beer 2010). Embracing this all-encompassing teaching philosophy aligns one to the heart of a learner and it is this passion to truly help another that shows in authentic, servant leadership with a genuine compassion.

Often in a project the common purpose or strategic goal, aligned with a mission and vision, 
forms a motivational common driver to succeed. If team members align with their own goals to that of the organisation, the employee will voluntarily go the extra mile, as they will be intrinsically motivated. This positive employee engagement and internal drive is a necessity in enabling an innovation culture and often drives one to engagement in an outside space. This leads to the motivation to engage and make a difference in other communities.

An interesting people-interaction enabling factor, critically important in increasing a culture of innovation, was the implementation of a mentoring program. This program allocated a trained science mentor to a specific school (RSA, DST 2017) who supported and mentored the learners in their projects for the science fairs. This support was invaluable and allowed close relationships to develop, facilitated guidance throughout the project development and increased the professional development of the educator. Outcomes of this intervention resulted in an increase in innovative projects which were application-based, with a high creativity level, as well as an increased motivation and interest in a wider range of the sciences. The opportunity to conduct a project in areas such as marine, astronomy and agricultural sciences allowed the learner, often at junior school level, to discover new areas of science not significantly covered in the curriculum.

Observations of outcomes and analyses from the narrative reports and experiences, within the people domain (educator, learner and community) of a science fair project, identified three sub-domain key enabling drivers towards innovative thinking: changed pedagogy, creative teaching strategies/teaching philosophy and mentoring. To unlock and open these pedagogical pathways of new thinking in the educator, catalyses the freedom of innovation and higher thinking in a learner. With practice and applications, learners can utilise these thinking skills in action and improve their innovative culture. If we can successfully embed this changed pedagogy in the scholarship of teaching and learning within both the educator and learner, it will become an intrinsic motivator for enabling an innovative thinking culture. Often a limiting factor in this domain is the restriction of time, as the curriculum is very full and teaching time can be short to allow completion of the required content.

\section{Place domain: Creative safe spaces, Transdisciplinary Spaces (TDS)}

To promote this innovative thinking culture, learners need to have freedom to analyse and synthesise, a process which needs to be practiced. It is key to create thinking spaces and opportunities where the learner can practice these. Aligned with the above viewpoint, De Beer $(2013,2)$ argues that in these spaces "knowledge is generated not in insulated spaces, but in real life contexts of local urban communities". Application-based discovery learning of the sciences occurs in these Transdisciplinary Spaces and this allows for higher engagement, 
teaching and learning (RSA, DHET 2013). By creating these skills in both the lower and middle value end of the education people chain (at a school level), one may ensure a better chance of success in developing innovators and researchers for the future, that can ultimately solve problems and create sustainable solutions in a critical manner.

The opportunity to be involved in Transdisciplinary Learning Spaces (TDS) such as science fairs or expos, including training and development workshops, catalyses the increase in both the attitude and skill level of research and knowledge. Ultimately this grows excellence in application-based research. The highest of the six levels of cognition are to evaluate and create (Anderson et al. 2001). It was observed that learners who had tackled science expo projects at junior school level were achieving a high standard of innovation skills at senior school levels, after continual exposure and participation in science projects and fairs. Science fairs and expos are both inter and Transdisciplinary Spaces, where they are given this opportunity for integrated higher level thinking (Duran and Dokma 2016).

With respect to the science fair experiences, these spaces may be at the school, university or district education offices, offering an inclusive space for action, reflection, dialogue and research sharing. It is in this safe learning space, that diverse groups of individuals can craft a common vision, theory and practice. Positive energy and divergent thinking is focused around a common theme, with the focus on research, innovation and science, technology, engineering and mathematics, thereby creating an Enabling Knowledge.

Enabling Knowledge, such as research skills and methods, require both educator and learner training. Communication skills, confidence and pride in their research builds trust in both the educators and the participants.

It was proposed by De Beer (2013) that the urban communities should not just be hosts for the engagements, but research partners and collaborators adding their voices and proposing solutions. It is in these spaces that dialogic reflection, scholarship of teaching and learning and inter-disciplinary actions take place. The science fair space provides this intersected space linking research thinking partners and collaborators. Ethical considerations and skills are also part of the project, research design and training.

The three sub-key common enabling drivers that were identified in the place domain for this research study in driving a high level of innovation are: application-inquiry-based science; teaching and learning spaces that build trust and safe spaces.

\section{Process/Purpose domain (Enabling Knowledge (EK)/common vision/team)}

The process of Enabling Knowledge is required to drive this innovative thinking, as content knowledge serves as a foundation. In examining the many sub-themes in this domain, the 
following were identified as critical constructs. Good communication of sound content knowledge and two-way dialogue are critical in this enabling process. Trust and team collaboration are necessary in safe spaces of both the educators and the learners. Both of these are imperative for allowing the freedom of thinking and creating an innovative culture, which need to be practised and become a mind-set change. A collaborative engagement approach with team work, creates an awareness and collegiality that can influence leadership and drive policy makers. In many cases, with low budgets and the driving of teaching and learning above community engagement in most universities, one observes that it often leads to a "vocabulary of engagement", with "no real practices for collaboration and change" (Preece 2012, 19). Petersen and Osman $(2013,17)$ agree that academic knowledge "defines and constructs knowledge but should also engage with knowledge created in other contexts". The centrality of CES between research, scholarship of teaching and service (Magaiza 2014) drives the discovery, reflection and collaboration of the academe and the community. To create this collaborative approach, requires a common vision and the alignment of strategic goals.

A common mission and vision or a common purpose is a unifying construct and it is in the project itself that the co-ordinating team needs to work with the same common purpose and be strategically aligned. Motivating, encouraging and inspiring young scientists as both educators and school learners, is critical. Common goals unite and instil passion and purpose.

Positive team collaboration between academe and communities to learn together, comprises an enabling factor that drives Enabling Knowledge to a higher level. It is in this interface that the integration is critical and it is in this space that Non-profit Organisations can provide links by interacting with government and providing Batho Pele ("People First") principles (Pitso 2014, 195). This integrated approach of academia and government with community becomes an active partnership in assisting with the achievement of common, relevant and strategic national goals.

In the traditional scholarship, knowledge Mode 1, is the disciplined, pure, hierarchical driven knowledge, which is found in higher education institutions (Kraak 2000; Gibbons 2003). Mode 2 knowledge production is considered "problem-solving knowledge" by Kraak $(2000,2-$ 3). This Mode 2 knowledge is intrinsic, inter- and transdisciplinary, trans institutional and heterogeneous. University strategies need to move increasingly towards Mode 2 knowledge to increase creative and innovative thinking and to be more effective in problem-solving with and within the community.

The benefit to both educators and learners participating in science projects and fairs, is that the love of discovering knowledge is stimulated. At a young age, learners can change and adapt their mind-set, become excited and motivated to learn and discover knowledge for a 
different reason, other than just passing an examination. It becomes a journey of learning not just an endpoint of passing or failing. This problem-based and inquiry thinking allow for intrinsic motivation to be stimulated.

It is known from literature sources that high performance teams drive an innovation culture (Darling-Hammond et al. 2010; Boedker et al. 2011; Orr and Orphanus 2013) and when a good volunteer team drives a project across boundaries, operating areas such as "generating knowledge not for, but with communities", gains are made in terms of scholarship of teaching and learning. There is also an increase in interdisciplinary efforts and public relevance (Franklin et al. 2008, 218) in creating alignment in a synergistically and beneficial relationship.

Another important enabler to be considered in driving innovation is the communication factor. Communication should be open, honest, positive and an open, two-way dialogue (Hoy 2010; Marlow et al. 2018). This genuine, high level of communication leads to the building of trust and integrity (Dee, Henkin and Singleton 2006). According to Robbins, Judge, Odendaal and Roodt (2014), communication can be considered pivotal in effective, high performing organisations and regarded as an enabler to drive innovation.

The three key common enabling drivers identified in the purpose/process domain for this research study in driving a high level of innovation are: common purpose/mission; dialogic (two-way communication) and teamwork/collaboration.

All of the above viewpoints are the researcher's own perspectives taken from observations, discussions, reports, meetings and journals, over the last few years in coordinating this community engagement project from the university. Based on the evidence collected over several years, the integrated proposed framework was constructed.

\section{Integrated proposed framework}

In this article, the researchers present a framework based on identifying the enabling factors that drive creative and innovative thinking skills of learners in transdisciplinary learning (e.g. science fairs). This framework outlines the benefit of Community Engagement Scholarship (CES) to produce Enabling Knowledge (EK), relevant to both the needs and social realities of the communities (Glassick, Huber and Maeroff 1997), within these Transdisciplinary Spaces (TDS) of science fairs.

Overall, these three pillars form the base of the pedagogical pathways, which are grouped into three domains: people (educator/learner/community engagement), place (creative/ transdisciplinary space) and purpose/practice (enabling knowledge/collaboration/team). As these are all on the continuum of relationships between the educator: learner: community, this forms the foundational basis of the framework. 


\section{RESEARCH METHODOLOGY}

This study used a qualitative methodology, with an auto-ethnographic narrative analysis in an exploratory research design. A constructivist, interpretive paradigm was selected for this study (Creswell 2009).

The auto-ethnographic research methodology is an emerging qualitative research method and is grounded in post-modern philosophy. It is linked to reflexivity and voice in social research (Wall 2006; Denzin 2013). We can define auto-ethnographic research as a method for reflexive research and practice, using narrative analysis (Wall 2006; Denzin 2013). In this research, the ethnographic data was situated within the person's own experiences and observations over the previous three-year period of co-ordinating a community engagement project. Journals and notebooks were kept over a period of three years, containing the researcher's observations, processes and reflections. Content analysis was used for the gathering and analysis of the textual content in words, meanings and themes (Neuman 2003). The researcher read the field notes, journals and transcriptions and identified "significant statements" (Creswell 2009) which provided, from textual descriptions, the essence of the key enabling factors required for the outcome of innovative thinking. To make these connections among identified and grouped elements from the data and construct a theoretical and conceptual framework, this research used ethnographic theory.

Three stages of the data collection process from the reflective journal writing and coding of the data can be outlined as follows: gathering data, focusing data and analysing data. The coding was manually coded, independently by the researcher on separate occasions and the coding frames were compared for reliability and validity by conducting an independent check by an outsider, who was not involved in the community engagement in this region (Struwig and Stead 2007). This method aims to construct a theory or conceptual framework by integrating the relevant literature and existing research alongside the researcher's own experiences in the community engagement spaces. Dependability was maintained through code-recode procedures and confirmability was established through triangulation and reflectivity.

The researcher combined both characteristics of autobiography and ethnography. In writing, the author has not lived through these experiences with the purpose of making them part of a published document, but they are assembled with a reflective practice (Freeman 2004). The author consulted others, used texts, photographs, journals, and recordings to recall experiences and observations (Didion 2005; Goodall 2006).

A participatory action research with an analytical auto-ethnographic methodology was used to examine the literature in this field and subsequently some key pillars of community 
engagement were identified and outlined in a theoretical framework (Figure 1).

From the data observed over the years within the community engagement space of science fairs where feedback from various sources was collected, a proposed framework was infused with the literature to co-create an innovation framework of enablers that showed the key pedagogical pathways. The researcher reflectively examined the journey of creating and driving innovative thinking and research skills in both the learners and educators within the engagement spaces and identified various key enabling drivers within the main domains.

The data analysis method used was based on emerging themes that were grouped into the three main domains in community engagement. The sampling was random purposive sampling in a longitudinal time frame study. This research was undertaken by a researcher who has coordinated a regional science fair with over forty to fifty schools, of approximately four to six hundred learners and over one hundred and fifty educators, every year, over the past fifteen years. However, journaling and notetaking was only seriously undertaken over the last three years. This research therefore utilises an auto-ethnographic approach, with ethical permission being granted from the main stakeholder of science fairs to publish this reflective analysis.

\section{DISCUSSION AND DEVISED FRAMEWORK}

Based on the evidence, observations and narrative findings by the researcher in the community engagement space, where the results of innovative thinking were a key performance outcome required, a draft framework with the relevant consulted literature was co-constructed, alongside experiences and observations. This resulted in the outlined, proposed framework to drive innovation in a community engagement space. After analysis and reflection, the following were identified as the critical, key enabling factors that drive innovation in the various domains. The nine main sub-domains of enabling factors that emerged from the research study observations and data collection were grouped under one of the main domains and are briefly unpacked in the proposed framework, within each of the three main pillars of the theoretical framework.

The infusing of the literature into the researcher's experiences led to the formulation of the proposed framework of enabling factors to drive innovation in an educational community engagement context (Figure 2).

This is the author's own construction of a proposed framework using the qualitative data and an auto-ethnographic approach. The main domains and enabling drivers are outlined as follows: A: People: A1 Pedagogy; A2 Teaching Strategies; A3 Mentor/Support; B: Place: B1 Application-based science driving high levels of critical thinking using inquiry; B2 Teaching and learning spaces; B3 Safe spaces/trust; C: Purpose/Practice: C1 Common purpose/ mission; C2 Dialogic Communication; C3 Collaboration and team. 


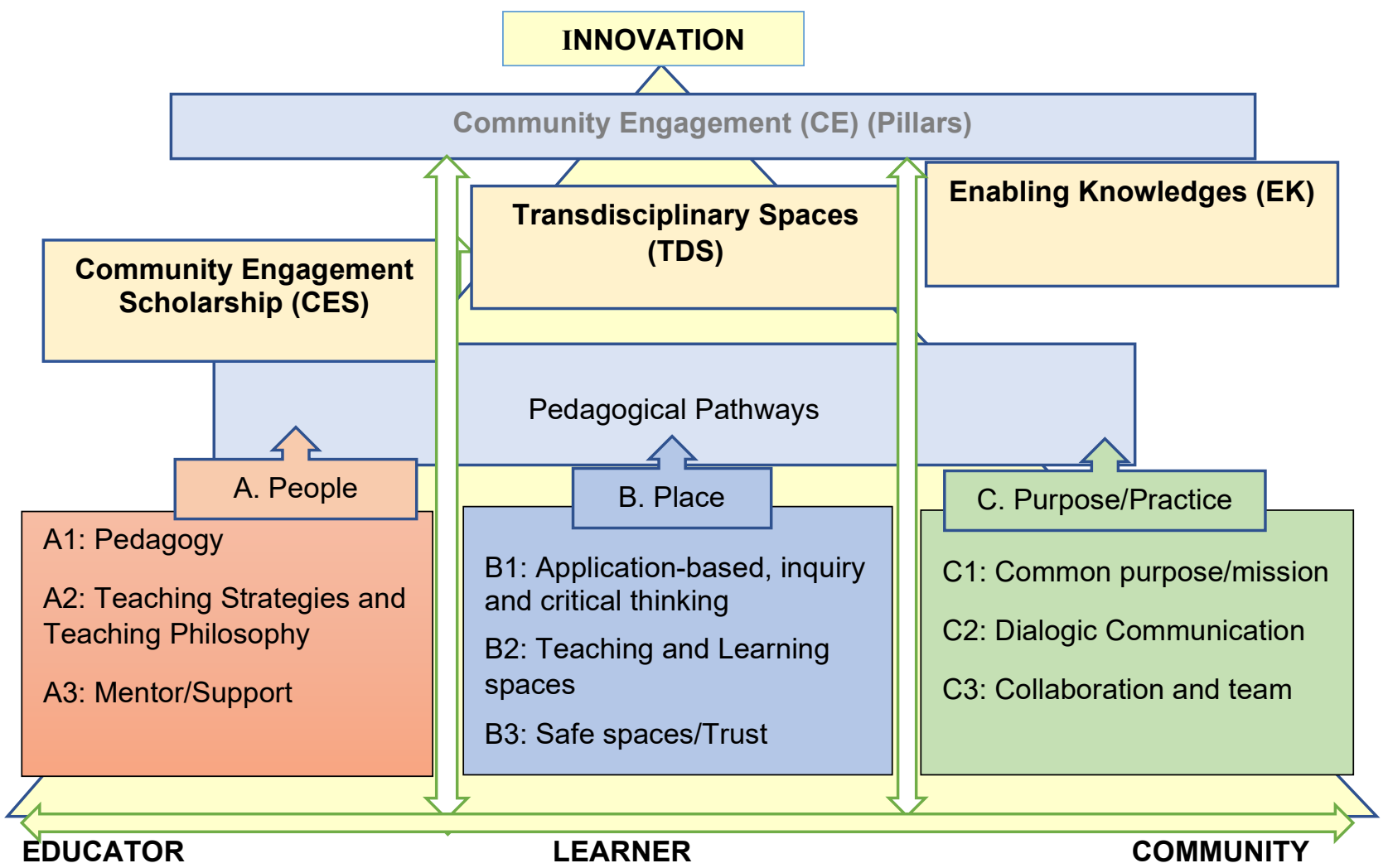

Figure 2: Framework of Pedagogical Pathways to drive innovation

Participation in science fairs was in a Transdisciplinary Space (TDS) and contributed towards a Community Engaged Scholarship (CES). It is postulated in this article that the integrated synergy of the CES and TDS showed beneficial reciprocal learning or Enabling Knowledge (EK). The synthesis of these factors create co-constructed skills, knowledge, values and attitudes for both the science educator and the learner participating in the science fair with their project. Identified key enabling drivers that were extracted from the reflections, journals and feedback of science educators, learners and the researcher-coordinator involved in the science fairs, indicated an increase in the Community Engaged Scholarship. Transdisciplinary thinking skills were expanded and the science fairs provided a channel of communication and safe space in which the scientific skills and knowledge were developed. The learning of the skill of science communication was also expanded and the confidence of both learners and educators increased over time as they presented their projects at different science fairs, at both regional and international levels.

Transdisciplinary Learning Spaces and sharing of Enabling Knowledge between academics and the community are drivers of higher creative thinking and innovation. Development from this experience leads to an unlocking of new pedagogical pathways which 
consist of enabling factors that ultimately drive higher innovation and creative thinking levels of both the educators and the learners. The application of this framework is to assist other researchers and practitioners working in this community engagement space to identify the enabling factors that drive innovation. By introducing some of these enabling factors into their strategies, it will open pedagogical pathways and other networks, to create a mutually enabling environment that encourages higher thinking order skills and leads to further innovative thinking.

This framework aligns with the literature on Community Engagement Scholarship (Gelman, Jordan and Seifer 2013) where they state the importance of the following five principles: scholarly investigations of real problems; problems defined by the community; collaborative knowledge development; institutional resource utilisation and shared authority in defining success. It is in this space that universities could lead discourses and problem-solving interventions for the social challenges in communities. It is an area that universities should utilise to share expertise outside of the academy (O'Meara and Rice 2005; Gelman et al. 2013).

Other work by Lerner and Simon $(1998,4)$ shows that this "bidirectional relationship of multiple stakeholders creates opportunities for innovation in theory, research, practice and policy machinations".

A limitation of this study is that it is only the first phase of the study and should be extended to empirically validate the data. This would expand and refine the framework and add validity and reliability.

Outcomes of this innovation culture drive other advantages. The community is involved in solving problems themselves. Indigenous knowledge is enabled in an application-based manner and teaching and learning become a two-way dialogic sharing.

There is collaborative development of knowledge to solve real, application-based research problems and this narrows the gap of communication issues between academe and communities. In this partnership, universities can share their expertise outside and within the communities and assist in solving some social challenges in communities.

\section{CONCLUSION}

A unique, proposed framework of key enabling factors contributing to driving an innovative culture in the field of community engagement was outlined. It is hoped that by improving strategies in both academe and communities, the third sector of Non-profit Organisations can make a significant contribution in driving the skill sets required for twenty first century learners of the future. The intersection of the university academe and the community is a neglected area of research, especially in the community engagement field and this article adds to the evidence 
and body of knowledge in this domain.

It is further hoped to expand this research to include empirical measures that could validate or adjust this framework with further contributing enabling factors that were not included in this research study. This proposed framework included three main community engagement pillars to drive innovation, which included the people (A), place (B) and practice/purpose (C), being Community Engagement Scholarship (CES), Transdisciplinary Spaces (TDS) and Enabling Knowledge (EK) respectively. These domains included several specific sub-domains that were identified in the community engagement space by the author, grouped as the pedagogical pathways important to drive innovation and higher order critical thinking skills. In the CES pillar, the sub-domains included a pedagogy, philosophy and teaching strategies that are inquiry based, learner-centred, encompassing mentoring and coaching. The TDS included application-based science with safe and trusting teaching and learning spaces. For the EK pillar, important sub-domains were identified as having a common and aligned mission and vision, collaborative teamwork and dialogic communication. All of these were found to drive this innovative culture in both educators and learners in a teaching and learning space, within this valuable community engagement space of science fairs.

\section{REFERENCES}

Adams, T. E., S. Holman Jones and C. Ellis. 2015. Auto-ethnography. New York, NY: Oxford University Press.

Albertyn, R. and P. Daniels. 2009. Research within the context of community engagement. In Higher Education in South Africa: A scholarly look behind the scenes, ed. E. Bitzer, 409428. Stellenbosch: SUN Press.

Anderson, L. W., D. R. Krathwohl, P. W. Airasian, K. A. Cruikshank, R. E. Mayer, P. R. Pintrich and M. C. Wittrock. 2001. A taxonomy for learning, teaching and assessing: A revision of Bloom's Taxonomy of educational objectives, abridged edition. White Plains.

Boedker, C., R. Vidgen, K. Meagher, J. Cogin and M. Runnalls. 2011. Leadership, culture and management practices of high performing workplaces in Australia: The High Performing Workplace Index. Australian School of Business, University of New South Wales, Society for Knowledge Economics.

Creswell, J. W. 2009. Research design: Qualitative, quantitative and mixed method approaches. $3^{\text {rd }}$ Edition. California: SAGE Publications.

Darling-Hammond, L., Meyerson, D., LaPointe, M., \& Orr, M. T. 2007. Preparing principals for a changing world. San Francisco, CA: Jossey Bass.

De Beer, S. 2013. Absence, presence, remembrance: A theological essay on frailty, the university and the city. Verbum et Ecclesia 34(1): 1-9.

Dee, J., A. Henkin and C. A. Singleton. 2006. Organisational commitment of teachers in urban schools. Urban education 41(6): 603-627.

Denzin, N. K. 2013. Interpretive auto-ethnography. Thousand Oaks, CA: Sage Publications. 
Didion, J. 2005. The year of magical thinking. New York: A.A. Knopf.

Donaldson, G. A. (Ed.). 2006. Cultivating leadership in schools: Connecting people, purpose and practice. $2^{\text {nd }}$ Edition. Amsterdam Avenue, New York, NY: Teachers College Press.

Duran, M. and I. Dokma. 2016. The effect of inquiry-based learning approach on students' critical thinking skills. Eurasia Journal of Mathematics, Science and Technology Education 12(12): 2887-2908.

Erasmus, M. and R. Albertyn. 2014. An introductory perspective on the knowledge enablement landscape. In Knowledge as enablement, ed. M. Erasmus and R. Albertyn 21-37. Stellenbosch: SUN Press.

Erasmus, M. and R. Albertyn. (Ed.) 2014. Knowledge as enablement. Stellenbosch: SUN Press.

Franklin, T. V., L. R. Sandman, N. E. Franklin and T. J. Settle. 2008. Answering the question of how: Out-of-region university engagement with an economically distressed, rural region. Journal of Higher Education Outreach and Engagement 12(3): 205-220.

Freeman, M. 2004. Data are everywhere: Narrative criticism in the literature of experience. In Narrative analysis: Studying the development of individuals in society, ed. Daiutte and Lightfoot, 63-81. Thousand Oaks, CA: Sage.

Gelman, S. B., C. Jordan and S. D. Seifer. 2013. Community-engaged scholarship in the academy: An action agenda. Change: The Magazine of Higher Learning 45(4): 58-66.

Gibbons, M. 2003. Innovation and the developing system of knowledge production. http://edie.cprost.sfu.ca/summer/papers/michael.gibbons.html

Glassick, C., M. Huber and G. Maeroff. 1997. Scholarship assessed: Evaluation of the professoriate. San Francisco: Jossey-Bass.

Goodall, B. H. 2006. A need to know: The clandestine history of a CIA family. Walnut Creek, CA: Left Coast Press.

Hoy, W. K. 2010. The organizational climate description. http://waynekhoy.com/ocdq-re.html

James, L., D. Guile and L. Unwin. 2013. Learning and innovation in the knowledge-based economy: Beyond clusters and qualifications. Journal of Education and Work 26(3): 243266.

K4C, UNESCO. 2017. Centre for Community Based Research. http://communitybased research.ca/Article/view/News Events/386

Kraak, A. 2000. Investigating new knowledge production: A South African higher education survey. In Changing modes, ed. Kraak. Pretoria: Human Sciences Research Council.

Krathwohl, D. R., B. S. Bloom and B. B. Masai. 1964. Taxonomy of educational objectives: Book 2: Affective domain. London: Longman.

Lerner, R. M. and L. A. K. Simon. 1998. The new American outreach university: Challenges and options. In University-community collaborations for the twenty-first century: Outreach scholarship for youth and families, ed. Lerner and Simon, 3-23. New York: Garland.

Liu, D., H. Liao and R. Loi. 2012. The dark side of leadership. Academy of Management Journal 55(5): 1187-1212.

Magaiza, G. 2014. Community engaged scholarship as pedagogy of possibility and knowledge enablement. In Knowledge as enablement, ed. Erasmus and Albertyn, 62-79. Stellenbosch: SUN Press.

Marlow, S. L., C. N. Lacerenza, J. Paoletti, C. S. Burke and E. Salas. 2018. Does team communication represent a one-size fits-all approach: A meta-analysis of team 
communication and performance? Organizational Behaviour and Human Decision Processes 144: 145-170.

Manning, J. and T. E. Adams. 2015. Popular culture studies and auto-ethnography: An essay on method. The Popular Culture Studies Journal 3(1 and 2): 187-222.

Neuman, W. L. 2003. The meanings of methodology: Social research methods. $5^{\text {th }}$ Edition. Boston, MA: Allyn and Bacon.

O’Meara, K. A. and R. E. Rice. 2005. Faculty priorities reconsidered: Encouraging multiple forms of scholarship. San Francisco: Jossey-Bass.

Orr, M. T. and S. Orphanus. 2013. Learning leadership matters: The influence of innovative school leadership preparation on teacher experiences and outcomes. Educational Management Administration and Leadership 1(21): 1-21.

Petersen, N. and R. Osman. 2013. An introduction to service learning in South Africa. In Service learning in South Africa, ed. Osman and Petersen, 2-32. Cape Town: Oxford University Press South Africa.

Pitso, P. 2014. Factors that promote or hinder the voice of the third sector in public service delivery. In Knowledge as enablement, ed. Erasmus and Albertyn, 195-213. Stellenbosch: SUN Press.

Preece, J. 2012. Community engagement in Africa. Common themes, challenges and prospects. In Community engagement in African universities: Perspectives, prospects and challenges, ed. Preece, Ntseane, Modise and Osborne, 215-229. Leicester: NIACE.

Robbins, S. P., T. A. Judge, A. Odendaal and G. Roodt. (Ed.). 2014. Organisational behaviour: Global and South African perspectives. South Africa: Pearson Education.

RSA, DST. 2013. Republic of South Africa: Department of Science and Technology. Strategy of Innovation Report.

RSA, DST. 2017. Republic of South Africa: Department of Science and Technology. Mentor program.

RSA, DHET. 2013. Republic of South Africa: Department of Higher Education and Training. White Paper for post-school education and training: Building an expanded, effective and integrated post-school system. Pretoria: DHET.

Struwig, F. W. and G. B. Stead. (Ed.). 2007. Planning, designing and reporting research. $4^{\text {th }}$ Edition. Cape Town, South Africa: Pearson Education South Africa.

Van Rooyen, H. and J. de Beer. (Ed.). 2010. Teaching science. Braamfontein, South Africa: Macmillan South Africa Publishers.

Van Rooyen, D. and W. Ellis. 2014. Enabling constructive engagement through knowledge of the non-profit sector. In Knowledge as enablement, ed. Erasmus and Albertyn, 179-194. Stellenbosch: SUN Press.

Wall, S. 2006. An auto-ethnography on learning about auto-ethnography. International Journal of Qualitative Methods 5(2): 146-160. 